\title{
Aesthetic Leadership Perceptions of High School Students Regarding Their Teachers ${ }^{1}$
}

\author{
Ejder Güven', Soner Polat ${ }^{2}$ \\ ${ }^{1}$ Kocaeli University, Faculty of Education, Institute of Social Sciences, Turkey \\ ${ }^{2}$ Kocaeli University, Faculty of Education, Department of Educational Sciences, Turkey \\ Correspondence: Ejder Güven, Kocaeli University, Faculty of Education, Institute of Social Sciences, Turkey.
}

Received: August 26, 2016

doi:10.11114/jets.v4i11.1839

\author{
Accepted: September 13, $2016 \quad$ Online Published: September 30, 2016 \\ URL: http://dx.doi.org/10.11114/jets.v4i11.1839
}

\begin{abstract}
The aim of this study is to examine the high school students' level of perception related to aesthetic leadership and its sub-dimensions and try to identify the characteristics of aesthetic leadership that have been displayed by their teachers in Kocaeli, Turkey. In this research, mixed research model has been adopted. At the end of the research, it has emerged that while the perception of aesthetic leadership characteristics that have been displayed by the high school students' teachers is frequent around "aesthetic appearance", the least highlighted aesthetic leadership quality is "aesthetic approach". According to findings of the research, it is appeared that the level of high school students' perception related to aesthetic leadership and its sub dimensions is medium level and high school students' perceptions do not differ significantly with respect to gender factor but high school students' perceptions differ significantly with respect to type and name of school.
\end{abstract}

Keywords: leadership, aesthetic, artistic leadership

\section{Introduction}

The concept of beauty has always been an indispensable element for the humanity throughout the history. A new problem area emerged for especially philosophy as a result that human being approached the beauty as a problem in a period that could be called early in terms of the history. This problem area is the aesthetic (Özden, 2002). Today, aesthetic phenomenon is as important as engineering skills (Smith, 1996). Communities which have a low level of aesthetic sense and pleasure may face with aesthetic pollution. The aesthetic pollution brings with many exaggeration and artificiality like bad tastes, poor quality, stationary and colorful designs and funny style of dress (Marinescu, 2010). This case causes to emerge loss of quality in not only insensitivity to environmental consciousness, indifference to historical and artistic works but also insensitivity to style of clothing, eating habits which are away from mutual politeness in society (Tebiş, 2010).

The society is exposed to irresponsibility in cultural and artistic works. This problem is closely related with the values of society. Fundamental values arising from the social needs can gain a sense of aesthetic values through artistic creation and they can go far from irresponsibility and artistic coarseness (Akdoğan, 2001). In this respect, one way to reduce the aesthetic coarseness and irresponsibility is to make society gain the aesthetic values. At this point, educational organizations have important duties. According to Kavuran (2003), arts education has a great importance on advancing awareness and pleasure in the level of aesthetic.

The common point where education and art meet together is the aesthetic phenomenon. At this point, concept of leadership has a key role to emerge the aesthetic values in a society by using education and art as tools so leadership is considered as a basic function by many organizations including educational institutions (Grunes, Gudmundsson \& Irmer, 2014). It is essential that leaders should be sensitive and creative models in terms of aesthetic in order to make up deficiencies in the level of aesthetic consciousness and pleasure (Polat \& Kavak, 2011).

\footnotetext{
${ }^{1}$ This study was produced from the mater thesis of Ejder Güven "High school students' perceptions of aesthetic leadership regarding their teachers" conducted under supervision of Assoc. Assoc. Prof. Dr. Soner Polat in Kocaeli University Institute of Social Sciences in 2014.
} 
Throughout the historical process, basic leadership theories are examined under four main heading as features theory: behavioral theory, situational theory, and new leadership theories (Bryman, 1992). One of the new leadership approaches is aesthetic leadership. Because leaders need a new leadership approach consisting of an ability that creates aesthetic judgment, perceptual position and a plausible explanation of the world (Woodwar and Funk, 2010).

\section{Conceptual Framework}

\subsection{Aesthetic}

The word of aesthetic whose root is Ancient Greek comes from the word 'aisthesis' or 'aisthanestha'. The word aisthesis means sensation. It means an interest and a curiosity on anything pleasing human feelings (Koehn \& Elm, 2014). Aesthetic includes information and meaning that is based on people's sensory experience about feelings, and emotions (Hansen, Sauer \& Ropo, 2007). Aesthetic, examining the components of beauty, tries to identify internal and external laws of beauty (Erinç, 1998).

Aesthetic structure may not always emerge in an organization directly; therefore, aesthetic features of leaders are needed to establish an aesthetic organization and protect available aesthetic values. Aesthetic perception in organizations emphasizes symbols and feelings on cognition and abstraction (Schroeder \& Fillis, 2010). Today, one of the ways of making a difference on increasing competitive conditions and strengthening organizational attractiveness is to create organizations having aesthetic values. For this reason according to Schroeder and Fillis (2010), the aesthetic leadership has an important place in leadership studies developing rapidly.

\subsection{Aesthetic Leadership}

Aesthetic leadership is defined as an approach focused on meaning and associated with sensory information and leadership phenomenon (Zhang, Cone, Everett \& Elkin, 2011). Aesthetic leadership is similar to different types of leadership style such as transformational, visionary, charismatic and authentic leadership in terms of some properties. According to Polat and Kavak (2011), aesthetic leadership is a leadership style that uses the aesthetic as an instrument and synthesizes transformational, charismatic and authentic leadership. In each leadership style, emotions have an important place for both leaders and their followers (Hansen, Ropo \& Sauer, 2007).

The reflection of extraordinariness and diversity concepts in the field of art in leadership causes to the emergence of aesthetic leadership (Fındıkç1, 2013). Aesthetic leaders share aesthetic vision with their followers and it is called as an influence process by displaying aesthetic behaviors such as criticism, sensitivity, emotion, attention and aesthetic pleasure (Polat \& Kavak, 2011). While aesthetic leaders make an organization's dreams true, they also make followers' dreams true (Vondey, 2012).

Aesthetic leadership style has seven sub-dimensions under the name of aesthetic appearance, aesthetic approach, aesthetic communication, aesthetic sensitivity, aesthetic honesty, aesthetic support and aesthetic application (Polat \& Kavak, 2011).

\subsubsection{Aesthetic Appearance}

Appearance constitutes an important part of a nonverbal communication. While the general appearance of a human reflects moods, emotions and feelings, physical appearance reflects characters, receptivity level and mental health (Sauer \& Ropo, 2007). According to Polat and Kavak (2011), not only aesthetic leaders have an internal aesthetic feature that is important, but also it is necessary to reflect their internal aesthetic leadership features with their body language and dressing style. So it can be said that besides appearance, aesthetic leaders have a high level of confidence against their followers, good communication skills and inner peace.

According to Schroder and Fillis (2010), aesthetic leaders transfer their mood, feelings and emotions with the help of their aesthetic appearance. In this transfer, physical experiences of aesthetic leader are in the center of learning. With the help of these experiences aesthetic leaders may help their followers seem in an aesthetic way (Sauer \& Rapo, 2007).

\subsubsection{Aesthetic Approach}

Aesthetic leadership which is an effective type of leadership maintains the relationship between followers and leaders in a harmonious way improves positive feelings around the organizations, becomes aware of their own environment clearly and follows common objectives and positive behaviors (Zhang, Cone, Everett \& Elkin, 2011). The most important objective of the aesthetic leaders, who try to understand and narrate the followers by focusing on their emotions and feelings, is to emerge the followers' aesthetic feelings (Samier, Batens \& Stanley 2006). According to Akdoğan (2001) and Carol (2012), aesthetic leaders who are not only free from their benefits and profits but also integrated with their followers approach them equally and impartially. When it is considered individual differences within an organization, it cannot be expected that everybody should have same opinion and philosophy of life. According to Kısaoğulları (2013), aesthetic leaders who try to emerge talents of their followers instead of their 
conflictions within organization have an integrated and unified approach against individuals having opposite ideas. It can be said that aesthetic leaders serve their followers like a bridge.

It is very important for aesthetic leaders not to look down their followers (Fındıkçı, 2013). Aesthetic leaders can solve the problems without giving any harm to anyone in social injustice, cultural issue and complex topics thanks to characteristics that they have (Schroder \& Fillis, 2010).

\subsubsection{Aesthetic Communication}

Art and aesthetic phenomenon gain meaning in a communication environment which especially stimulates perceptions (Erzen, 1976). Not only creating a vision is important for a leader but also it has a vital importance for the followers to communicate as they dream for a positive future (Vondey, 2010). In this communication process, aesthetic leaders keep their followers together thanks to their gentle calm and analytical attitude (Kavak \& Polat, 2011). As for the followers in organizations, it can be stated that they have adapted to the environment far from hierarchy with the help of leaders' aesthetic communication skills.

According to Sauer and Ropo (2007), aesthetic leaders keep-themselves away from criticism if they are perfect and balanced in communication. In this context, the body languages of aesthetic leaders who use their own feelings is so controlled. Thanks to their aesthetic skills, aesthetic leaders convert meanings into shapes, make verbalization, convert dreams into images and put the intellectual atmosphere of humanity as a whole into words and lines (Fındıkç1, 2013).

\subsubsection{Aesthetic Sensitivity}

People who have aesthetic sensitivity are so sensitive to environment that more they see, more they hear and more they read (Smith, 1996). The aesthetic sensitivity increases thanks to individuals' aesthetic education. Thus, individuals are able to realize beauties around them easily. The individuals, whose aesthetic sensitivity has increased, can easily overcome problems that may arise in the terms of aesthetic (Polat \& Kavak, 2011).

Aesthetic leaders force their followers to see unique beauty, think about their nature and their great universe, understand and comprehend in terms of aesthetic (Fındıkçı, 2013). At this point, the main purpose of aesthetic leaders is to examine different feelings and give opportunities their followers by focusing characteristics of the work of art (Bozkurt, 1997). Thanks to aesthetic sensitivity, aesthetic leaders can help their followers participate in artistic activities (Polat \& Kavak , 2011).

\subsubsection{Aesthetic Honesty}

Aesthetic leaders, who never hide anything from their followers, are transparent about everything. The distinguishing feature of aesthetic experience is to be 'disinterested' (Bozkurt, 1992). Aesthetic leaders are consistent with their acts and discourse. In this context, it is important that the aesthetic leaders make their followers feel the concept of aesthetic honesty properly. So, aesthetic leaders are the leaders who give permission that they can carry out; otherwise, the followers may lose their confidence against their leaders if they break their promise against their followers (Vural, 1997).

\subsubsection{Aesthetic Support}

Aesthetic leaders help their followers emerge their aesthetic potential and reward them at the same time (Polat \& Kavak, 2011). Aesthetic leaders can be thought like architects because they structure the environment more humanly, more thoughtfully and more aesthetically (Saminer, Bates \& Stanley, 2006).

Aesthetic leaders support the followers aesthetically in an effective management and planning policies by providing them appropriate environment and opportunities (Erbay, 2009). Thanks to aesthetic support, leaders can meet in a common point and a collective environment with their followers. At this meeting, there is no matter of differences between place and time for aesthetic leaders and their followers. It can be stated that the meeting with their followers is the unique work of aesthetic leaders (Findıkçı, 2013).

\subsubsection{Aesthetic Application}

Aesthetic leaders are like an art critic (Polat \& Kavak, 2011). The purpose of leaders who try to create an artist is not to present an issue instead they reveals it with their followers (Ruen, 2010). It can be said that aesthetic leaders use aesthetic experiences they have in this process. Ongjenovic (1997) has identified aesthetic experiences as a special and objective relationship. Thanks to aesthetic experience, aesthetic leaders can access the resource of aesthetic knowledge with their followers easily (Babai, Damirchi \& Sharifi, 2013).

Aesthetic leaders who offer a new aesthetic meanings by bringing their dreams into a real life don't put pressure on their followers even they give chances to them in order to improve and express themselves (Find1k, 2013). Aesthetic leaders don't have any expectations and interests in the applications of aesthetic life so their purpose is to create an aesthetic 
critic from their followers with aesthetic applications (Polat \& Kavak).

\section{Research Questions}

The main guiding this research is to study aesthetic leadership model in a mixed model study in high schools and examine the impact of teachers' aesthetic leadership implications on students. Based on this main guided question, the objectives of this study are stated as follows:

1. According to high school students, 'What are the levels of high school teachers' displaying features of aesthetic leadership and its sub-dimensions; aesthetic appearance, aesthetic approach, aesthetic communication, aesthetic sensitivity, aesthetic honesty, aesthetic support and aesthetic application?"

2. 'Do the perceptions of high school students regarding their teachers' aesthetic leadership behaviors and its sub-dimensions differentiate according to gender, type of school and school name meaningfully?"

3. According to students, "what are features of high school students' teachers as an aesthetic leader?"

\section{Methods}

\subsection{Model of Study}

This research has been designed in quantitative and qualitative research methods (mixed method). The study design has been created with using an asynchronous mixed model. Using quantitative and qualitative research method together provides the researchers to understand the research questions better in comparison with using the both research models one by one (Cresswell, 2003). The descriptive research model of the quantitative data collection methods was used to determine the level of high school students' aesthetic leadership perceptions regarding the behaviors that their teachers display. To determine the teachers' aesthetic leadership characteristics according to perception of high school students, phenomenological research design was used in qualitative research.

\subsection{Population and Sampling}

The population of this study is composed of the students who have studied in high schools located in Kocaeli, Turkey. The population of the study consists of 2907 students in $12^{\text {th }}$ class from 18 high schools in Kocaeli, in 2013-2014 academic years. Sampling of the study comprises 7 high schools of which are 4 general high schools and 3 technical high schools. Deliberate sampling method was used as displaying the teachers' aesthetic leadership characteristics needs time and interaction. Aesthetic leadership scale was distributed to 1049 students but only from 647 students answered the scale. 622 scales were used for producing data. From 622 students who have participated in the data processing, 292 of them are female, 330 of them are male. The study groups of the research consist of 21 students who have been 3 different high schools in Kocaeli, in 2013-2014 academic years.

\subsection{Data Collection Instruments}

The quantitative research data has been gathered using "Aesthetic Leadership Scale" having 51 items with 5 likert-type, developed by Polat and Kavak (2011). In the Aesthetic Leadership Scale, 10 items measure the size of the aesthetic support, 10 items measure the size of the aesthetic application, 9 items measure the size of aesthetic approach, 8 items measure the size of aesthetic communication- 6 items measure the size of aesthetic sensitivity, 4 items measure the size of the aesthetic honesty and 3 of them items measure the size of aesthetic appearance. The semi-structured interview form having 7 main guiding questions was used to gather qualitative data research.

\subsection{Data Analysis}

In the analysis of quantitative data, arithmetic mean were used in order to determine the level of aesthetic leadership and its sub-dimensions; aesthetic appearance, aesthetic approach, aesthetic communication, aesthetic sensitivity, aesthetic honesty, aesthetic support and aesthetic application. When arithmetic means are interpreted, intervals have been valued as: $1.00-1.79$ "very low", $1.80-2.59$ "low", 2, 60 - 3,39 "medium", 3.40 - 4.19 "high", 4.20 - 5.00 "very high". ANOVA and t-test were used in order to understand whether high school students' perceptions related to their teachers' aesthetic leadership and its sub-dimension levels change or not.

In the analysis of qualitative data, students' responses taken from semi-structured interview questions were coded. Students'-names were given as S1...S21 without written their name. By mentioning students' original expression and utilizing the literature, findings were evaluated and interpreted in order to support.

\section{Findings}

\subsection{Findings Regarding First Research Question}

First research question is designed as "According to high school students, what are the levels of their teachers' aesthetic leadership and its sub-dimensions; aesthetic appearance, aesthetic approach, aesthetic communication, aesthetic 
sensitivity, aesthetic honesty, aesthetic support and aesthetic, displayed by their teachers". The level of high school teachers' displaying aesthetic leadership behaviors seems to be at medium level $(X=3.29)$.

Table 1. According to high school students, high school teachers' aesthetic leadership and the level of showing its sub-dimension regarding to arithmetic mean and standard deviation values

\begin{tabular}{llll}
\hline Variables & $\mathrm{N}$ & $\mathrm{X}^{-}$ & $\mathrm{Ss}$ \\
\hline Aesthetic Appearance & 622 & 3.49 & 1.02 \\
Aesthetic Communication & 622 & 3.38 & 0.82 \\
Aesthetic Honesty & 622 & 3.33 & 1.00 \\
Aesthetic Sensitivity & 622 & 3.33 & 0.93 \\
Aesthetic Support & 622 & 3.29 & 0.87 \\
Aesthetic Application & 622 & 3.23 & 0.91 \\
Aesthetic Approach & 622 & 3.21 & 0.81 \\
Total Average & 622 & 3.29 & 0.76 \\
\hline
\end{tabular}

As it is seen on the table, according to the high school students, teachers' aesthetic appearance from their aesthetic leadership's sub-dimensions seem to be at high level( $\mathrm{X}=3.49)$. Aesthetic communication follows this sub-dimension with $\left(X^{-}=3.38\right)$, aesthetic honesty $\left(X^{-}=3.33\right)$, aesthetic sensitivity $\left(X^{-}=3.33\right)$ aesthetic support $\left(X^{-}=3.29\right)$, aesthetic application $\left(\mathrm{X}^{-}=3.23\right)$ and aesthetic approach $\left(\mathrm{X}^{-}=3.21\right)$.

\subsection{Findings Regarding Second Research Question}

Second research question is designed as 'Do the high school students' perceptions regarding displaying of their teachers aesthetic leadership behaviors and its sub-dimensions differentiate meaningfully according to gender, types of school and names of school?". $\mathrm{t}$-test $(\mathrm{t}=0.44, \mathrm{p}>05)$ was used in order to control whether students' perception score regarding their teachers' aesthetic leadership and its sub-dimensions change or not related to gender. But, it isn't seen a significant difference. $\mathrm{t}$-test $(\mathrm{t}=2.52, \mathrm{p}<05)$ was used in order to control whether students' perception score regarding their teachers' aesthetic leadership and its sub-dimensions change or not related to types of school. And it is seen a significant difference. It can be observed that the general high school students' perception level $\left(\mathrm{X}^{-}=3.35\right)$ related to aesthetic leadership and its sub-dimensions are higher than technical high school students' perception $\left(X^{-}=3.19\right)$. ANOVA $(\mathrm{F}=5.25, \mathrm{p}<05)$ was used in order to control whether students' perception score regarding their teachers' aesthetic leadership and its sub-dimensions change or not related to names of schools. And it is seen a significant difference.

\subsection{Findings Regarding First Research Question}

The third research question is 'What are features of high school students' teachers as an aesthetic leader?" and it was seen that the students' answers were gathered in 7 themes. These themes are consistent with sub-dimensions of the scale in which were gathered quantitative data.

\subsubsection{Findings Regarding Teachers' Aesthetic Appearance}

Students in study group stated that teachers usually influence them with their aesthetic appearance. It is stated that the stylish and trendy clothing of teachers are visual examples for students (20 participants). It is emphasized that teachers who follow the fashion are open to changes and they are innovative, planned and scheduled (6 participants). It is stated that teachers who have aesthetic appearance are extraordinary, attractive and they have a greater impact on students than ordinary teachers ( 3 participants). It is mentioned that teachers who adapt to students quickly offer creative ideas and collect the students' interests on their own with their fascinating appearance ( 3 participants). It was expressed that teachers' positive body language influences students in a delighted way (2 participants). It is indicated that eye pleasing teachers with their appearance are taken as an example by students and also students pay attention their appearance (1 participant). It is reported that teachers who make an example with their appearance a higher eloquence and good dictation (1 participant).

It is clearly stated in the following definition from some of the participiants:

"Teachers in our school take care their appearance. They wear fashionable clothes and we imitate them as students".(S4)

'Our teachers are a bit extraordinary because they don' $t$ wear frumpish clothes so they are noticed in a society easily and we take them as a model". (S8)

"We are interested in fashion very much. Most of our teachers are a good model with their clothing style and appearance. Especially female teachers take care their appearance. They make up meticulously everyday, they smell nice and they don' $t$ wear same clothes for each school day".(S11)

'Our teachers are cute and they influence us with not only their creative fashionable clothing style but also their positive gestures and mimics".(S15) 


\subsubsection{Finding Regarding Teachers' Aesthetic Approach}

The students in the study group evaluated the teachers' aesthetic approach towards them positively. It is expressed that teachers behave in an emphatic way and thus this relieves students (10 participants). It is expressed that teachers solve the problems in a calm and controlled way (5 participants). It's stated that the majority of teachers approach each student fairly under the equal conditions (4 participants). It's been mentioned that teachers are creative and they provide opportunities for the students on variety of subjects (2 participants).

Some of the participiants explain:

' Artistic tools such as songs, pictures or books are like bridges between teachers and their students. With the help of these bridges, teachers and their students meet in a common point, share same feelings and see the same beauties. Our teachers approach us without judging in an emphatic manner with the help of the bridges that we have constructed mutually". (S6)

'Our teachers approach and behave my friends me indulgently so their aesthetic behavior relieves us'. (S13)

"Our teachers don't give any decision about us urgently. I can tell that our teachers are calm and patient while they are approaching us. I always liken them with artists because both of them never want to spoil their work". (S19)

"Teachers in my school are friendly, sincere and good-humored in their approach to the students. In, my opinion they leave their problem at home and approach us as if we were their masterpiece". (S21)

\subsubsection{Findings Regarding Teachers' Aesthetic Communication}

Students in study group have stated that teachers have used the aesthetic communication effectively. The teachers having effective aesthetic communication aren't swelled head even they are in a complementary manner to the students (11 participants). It is stated that teachers are sincere, frank and thoughtful when they communicate with students $(6$ participants). It is also reported that teachers are in friendly, cheerful, approach towards the students (5 participants). It has been emphasized that the teachers have tried all ways to reach students in an interaction ( 5 participants). It has been said that the teachers have motivated students and approached them without any prejudice ( 3 participants). It has been stated while teachers are overcoming problems, they use different extraordinary and remarkable methods (2 participants).

Explanations of some participants are:

"When our teachers having aesthetic features try to solve the problems about us, they give us different and logical solutions. They don't see the world as the ordinary teachers do. They use strong communication channels". (S1)

"Our teachers are not bighead; on the contrary, they display altruistic attitude toward us. They don't blame us". (S7)

"Our teachers are sincere toward us and they are always open to communicate. Whenever my friends and I want to talk about something with them, they never reject us. We can share all our problems with them". (S12)

"Most of our teachers aim to motivate us not only in lesson but also outside of the lesson with their artistic features. They use their impressive and artistic language and ability to motivate us. For example, they make us believe about reaching our target by using their language ability”. (S17)

\subsubsection{Findings Regarding Teachers' Aesthetic Sensitivity}

All students in study group have stated that most teachers have an aesthetic sensitivity. It has been emphasized that teachers are models and leaders for students firstly by behaving aesthetically so that students gain aesthetic sensitivity (8 participants). It has been stated that the teachers who emphasize the aesthetic sensitivity are creative, open-minded and innovator (5 participants). Teachers arrange the organizations such as trips to the nature and planting in order to make students gain aesthetic sensitivity (4 participants). It has been said that some courses to popularize nature and trees, have been made and wastes have been gathered together ( 3 participants). It has been said that teachers have been paid attention to a garden layout and its cleaning ( 2 participants).

Explanations of some participants are:

"'Our teachers do something first themselves to bring aesthetic consciousness for their students. By this way, my friends and I take them as a model for us. For example, we arranged a competition in our school during the last educational year. We aimed to choose the cleanest classroom in school. Our teachers were role model for us because they always warned us not to pollute the environment and they never made dirty the environment. They always wore clean clothes, threw their rubbish into the rubbish bin and washed their hands if they were dirty. I can say that they made us gain the awareness of aesthetic sensitivity". (S5)

\footnotetext{
'"Three years ago, our library was messy. Thanks to aesthetic sensitivity of our teachers, it is tidier now. They put
} 
colorful chairs, tables and computers there. They increased number and types of the books. We have fun to read something and spend time there”. (S8)

"'We don't always have lesson in the classroom. Sometimes, our teachers take us to the school garden. We clean the environment, collect the rubbish and watch the nature together. They organize nature trips for us. These activities help us gain aesthetic awareness". (S16)

"'We have smart boards in schools. We watch the films and documentaries having artistic message with our teachers". (S18)

\subsubsection{Findings Regarding Teachers' Aesthetic Honesty}

The participant students have stated that most teachers influence their students by displaying behaviors related to aesthetic honesty. It has been expressed that teachers who have aesthetic honesty are clear and consistent against students and also that is the same what they do and say (10 participants). It has been expressed that teachers who affect students with their own aesthetic honesty are critical but constructive, controlled and they make empathy (4 participants). It has been mentioned that teachers exhibit positive attitudes by themselves firstly which they want to make students create (4 participants). It has been reported that teachers are creative but they are not dreamers $(2$ participants).

Explanations of some participants are:

"'I think that most of our teachers are consistent and they are open to understand. For example, our literature teacher never recommends us any book s/he doesn't like. First, s/he reads the book and then recommends us what to read. S/he never behaves as if s/he liked the book if s/he recommends it for us". (S3)

"'One of my teacher used to smoke last year and gave up smoking. Not only s/he always warns us not to smoke but also s/he doesn't really smoke”. (S10)

' Our teachers take care our appearance especially at school. They warn us not to wear messy clothes and advise us to be careful about our appearance and health. They behave as they advise us. By this way, they display their feature of aesthetic honesty". (S11)

"'Our teachers have visions. They usually achieve their visions. For example, our art and music teacher had a vision related to a huge celebration at the end of the school day. They worked hard during the year and kept their promise toward the students. It was like a carnival and fascinating aesthetic fast”. (S17)

\subsubsection{Findings Regarding Teachers' Aesthetic Support}

The participant students have stated that teachers always support them in order to make students gain aesthetic features. It has been reported that teachers support and direct the students according to their abilities ( 7 participants). It has been reported that teachers use every opportunity in order to gain students aesthetic qualities and also they are motivated (5 participants). It has been mentioned that teachers give students support in all kind of educational and artistic activities by waking their feelings of freedom and friendship. While they are doing this, they don't expect anything in return from students (4 participants). Teachers support students psychologically (1 participant). It has been said that teachers instill confidence in students and encourage them (1 participant).

It is clearly stated in the following definition from some of the participants:

' 'My friends and I can reach all opportunities in school thanks to help of our teachers. Without judging, they support us in our organizations. For instance, our sport uniforms were a bit old fashioned. S/he and school authority supplied new and fashionable sport uniforms for us to look better”. (S6)

'I am fond of drawing. Art teacher in school always motivates and support me to draw much more pictures. If I don't have enough drawing materials, s/he buys them for me. S/he always encourages me not to give up and tells me human being learns by making mistakes". (S8)

'Our teachers help us gain our self-confidence. Music teacher in school wants us to play the flute repeatedly without judging us. Thanks to his/her support, I can play the flute well”. (S15)

' 'Every year, theater performances are displayed in our school. I am always interested in acting. Thanks to literature teacher's support in school, my dreams came true. Although I was younger and more inexperienced than other performers, s/he gave me a chance and believed me to achieve my goal". (S19)

5.3.7 Findings Regarding Teachers' Aesthetic Application

Generally, students have reported positive opinion on teachers' aesthetic application. Students have expressed that their teachers do social activities with them, teach them to think freely, influence them with their eye-pleasing behaviors and 
give lessons spicily and entertainingly (18 participants). It has been reported that a lot of concerts take place in school. Music, theatre and pictures are providers in personal development and they are made for students in order to make aesthetic applications more effectively (10 participants). It has been said that teachers respect students thoughts and they instill them love (9 participants). It has been stated that teachers are models for students with their behaviors and they transfer their positive life experiences to the students ( 5 participants). On the other hand, it has been emphasized that teachers are good examples with their clothing (5 participants). It has been stated that teachers stay away from habits such as smoking in order not to set a bad example (3 participants). It has been reported that students read and write poems and compositions ( 3 participants). It has been stated that a variety of visual materials such as educational videos are used to make more efficient courses in terms of aesthetic (1 participant).

Explanations of some participants are:

"Teachers in school are aware that they should be model for the students. For instance, some of our teachers sing a song and they encourage us to sing. Some of them write poems and they help us write nice poems. Some of them draw and they foster us to draw nice pictures. With their help, we as students have an opportunity to solve the problems in different ways". (S10)

"Social activities have an important place in our school. For example, students go to cinema, trekking, picnic and theatre with their teachers". (S13)

"Our teachers explain how to solve a problem by simplifying it. If teachers want us to teach something, they use music, films, pictures and plays". (S16)

"Our teachers respect us. If we fail in something to do, they never insult us. While our teachers are displaying us how to do something, they use their experiences". (S21)

\section{Result and Discussion}

According to high school students, their teachers display the aesthetic leadership features at 'medium level' but the study done by Polat and Kavak (2011) shows that according to teachers, the school principals exhibit the aesthetic leadership features on the 'high level'. In this case it can be said that teachers can't exhibit their aesthetic leadership behaviors as effective as principals do. According to students, the teachers exhibit only the aesthetic appearance at 'high level' from the sub-dimensions of aesthetic leadership. The size of this order is followed such that the aesthetic communication, aesthetic honesty, aesthetic support, aesthetic application, aesthetic approach are at 'medium level'. Teachers are model for students with their aesthetic appearance. The most remarkable element on students is teachers' 'impressive and eye-pleasing appearance, having image may cause a sub-dimension of aesthetic appearance to have "high" value. In the study which was done by Polat and Kavak (2011) is seen that the lowest average belongs to the sub-dimension of the aesthetic approach. This result obtained in both surveys can be interpreted like that although teachers have an aesthetic appearance; they don't lead to students' on aesthetic approach behaviors. In addition that the aesthetic appearance which is more measurable and observable may also be effective to be high for teachers' and students' aesthetic appearance perceptions. Other of the aesthetic leadership necessitate interaction with followers. Therefore, observed observation and measurement depend on the existence of interaction. Another result of this study, gender doesn't create a significant difference on the level of the aesthetic perception that students have. This result is consistent with the result of the study done by Polat and Kavak (2011). Types of school variance have created a significant difference on the level of aesthetic leadership perceptions of high school students regarding their teachers. General high school students, compared to vocational technical high school students, think that their teachers show a higher level of aesthetic leadership behaviors. This result is consistent with the study done by Polat and Kavak (2011). Thus, aesthetic leadership is thought to be influenced by the organization culture which is based on school variance. The factors such as students 'academic levels, differentiating the students' aesthetic expectations from their teachers may lead to differentiate the aesthetic perceptions of high school students regarding their teachers according to type of school.

Increasing level of perception and pleasure can lead to positive results for both people and environment in today's society in which the level of aesthetic perception and pleasure are deficient. It can be said that the greatest role belongs to the education in order to increase and gain the level of aesthetic perception and pleasure. At this stage, it can be reported that educational institutions have an important role and the teachers who are the headstones of the educational institutions, play a key role in this context. Katz-Buonincontro (2011) emphasizes the importance of educational institutions for teaching the aesthetic values and points out the relationship between teachers and students for emerging the aesthetic leadership behaviors in her study. At this point, aesthetic leadership behaviors that both students see on their teachers have been examined thoroughly. The characteristics of aesthetic sensitivity, aesthetic approach, aesthetic communication, aesthetic appearance, aesthetic application, the aesthetic honesty and support that the teachers display should be focused more extensively on this study while the analysis is being done. 
In qualitative research, it has been tried to find out which properties of high school students' teachers have affected them aesthetically. According to students, teachers who wear trendy clothes and use their body languages efficiently affect them aesthetically. Teachers are also innovative, creative, remarkable and extraordinary, in respect of students. According to Taylor and Hansen (2005), aesthetic appearance emphasizes the importance of appearance physically in leadership. According to Sauer and Ropo (2007), the followers follow the leaders with the help of their bodies that they feel and experience. In this case, it can be said that teachers being imitated by the students are good examples with their aesthetic appearance for them.

Students expect an aesthetic approach on the solution of problems and relation with their teachers when teachers exhibit calm, controlled, professional manners and establish empathy and the solution of problems. According to Hansen and Taylor (2005), aesthetic approach is related with a combination of feelings that people have and it focus on experiences. In this context, it can be said that teachers' behaviors that they exhibit professionally with empathy and in a controlled manner help the students' feeling bring together aesthetically.

One another feature that students are impressed from their teachers as an aesthetic leader is the aesthetic communication. The students have stated to take teachers as an example when teachers use I language instead of you language. Teachers are gentle in their sentences when they communicate aesthetically, sincerely, friendly and they also establish empathy on students. According to Dop (2006), time and field that the aesthetic leadership provides for the followers, develop informal communication being used in order to build confidence for them. Gültekin (2011) has indicated that ways to adapt to the world in which people live pass through the art of communication in the social life and develop communication skills with the help of art. In this case, it can be said that teachers offer opportunities to students without unbiased manner, frankly and arise the feeling of confidence thanks to their aesthetic communication skills.

Students have expressed that they are influenced aesthetically from their teachers when they are sensitive against to events and objects According to Polat and Kavak (2011), it is needed to create the aesthetic perspective on people in order to get rid of the objects and events that don't have any aesthetic values. In this study it can be said that students distinguish events and objects thanks to the aesthetic sensitivity that they learnt from their teachers.

Students expect aesthetic honesty from their teachers. Students find their teacher more convincing when they are consistent with what they say and do. The students are impressed by their teachers that they trust. According to Brown and Mitchell (2010), teacher is a kind of leader behaving honestly, accurately and fairly in order to apply the actions. It can be said that the teacher displaying aesthetic honesty help students gain aesthetic aspect by conducting them honestly. Especially, teachers that direct the students by using aesthetic behaviors, creations and lead them by evaluating their aesthetic creations and behaviors influence students more in terms of aesthetic. According to Taylor and Hansen (2005), aesthetic application includes language skills, listening skills, looks, touching, feelings and emotions as an important source of knowledge. According to Hansen, Ropo and Sauer (2007), leaders who apply aesthetic application have a great potential in themselves. So, it can be said that teachers having aesthetic features support the students aesthetically by looking at the world more differently than ordinary people do.

Students have expressed that they are influenced more by the situations which they can observe and see aesthetically. Teachers who attempt to concrete on aesthetic interference by doing social artistic works in order to develop social consciousness influence their students much more. According to Mamur (2012), courses need to be configured again with the approaches that aim in the teachers' aesthetic thoughts, critical thinking abilities on art and development of aesthetic sensitivity. In this study, it can be said that teachers have more effective courses with aesthetic, eye-pleasing activities and in this wise they have greater impacts on students.

\section{References}

Akdoğan, B. (2001). Art, Atist, Artwork and Ethics. A.U. Journal of Faculty of Theology, 11(2), 212-245.

Babai, M., Darmichi, Q., \& Sharifi, S. (2013). Problem Solving in Content of Aesthetic Management. Australian Journal Of Basic And Applied Sciences, 7(1), 295-301.

Bozkurt, N. (1992). Art and Aesthetic Theories (2. Edition). İstanbul: Ara Publishing.

Brown, M. E., \& Mitchell, S. M. (2011). Ethical And Unethical Leadership. Business Ethics Quarterly, 20(1), 583-616.

Bryman, A. (1992). Charisma and Leadership In Organizations. London: London. Sage.

Carrol, N. (2012). Philoshophy of Art. GÜLiz Korkmaz Tirkeş (Trans.). Ankara: ÜTopya Publications.

Creswell, J. W. (2003). Research Design: Qualitative, Quantitative, And Mixed Methods Approaches (2nd Ed.). Thousand Oaks, CA: Sage.

Dop, J. S. (2006). Aesthetic Leadership: Stories of Support, Relationship, and Success among Novice Teachers And School Administrator. Nebraska: University Of Nebraska Press. 
Erbay, M. (2009). Art, Art Management and Beyond. Journal of Critics, 2, 37-41.

Erinç, S. M. (1998). Inntrodustion to Psychology of Art. Ankara: Ayraç Publishings.

Erzen, J. N. (1976). The Review of Education as an Aesthetic Process and Arthitectural Education. Metu Education Library, 2(2), 175-186.

Fındıkçı, İ. (2013). Servant Leadership. İstanbul: Alfa Printing and Publishing.

Grunes, P., Gudmundsson, A., \& Irmer, B. (2014). To What Extent Is The Mayer And Salovey (1997) Model of Emotional Intelligence A Useful Predictor of Leadership Style and Perceived Leadership Outcomes in Australian Educational Institutions?

Gültekin, T. (2011). In Art Education And In The Process of Development of Aesthetic Values Child and Communication. E- Journal of International Peer-Reviewed Social Sciences, 1-14.

Hansen, H., Ropo, A., \& Sauer, E. (2007). Aesthetic Leadership. Leadership Quarterly, 18(6), 544-560. http://dx.doi.org/10.1016/j.leaqua.2007.09.003

Katz-Buonincontro, J. (2011). How Might Aesthetic Knowing Relate To Leadership? A Review of the Literature. International Journal of Education \& the Arts, 12(1), 1-18.

Kavuran, T. (2003). The Concept of Reality İn Art And Science. The Joural of Firat University Social Sciences Institute, 15(2), 225-237.

Kısaoğulları, A. (2013). Art Management and Art Director. Journal of Ulakbilge Social Sciences, 1(1), 36-43.

Koehn, D., \& Elm, D. (2014). Aestheics and Business Ethics. New York: Springer Science Business Media. Http://Dx.Doi.Org/10.1007/978-94-007-7070-6

Mamur, N. (2012). Examining Of Kitsch Phenomenon İn Terms Of Aesthetic Appreciation İn Art Education. Journal of Mersin University Faculty of Education, 8(3), 70-79.

Marinescu, D., \& Truşca, P. (2010). Visual Pollution and Aesthetic Education. Christian University, 41-45.

Ognjenovic, P. (1997). Psychological Theory of Art. Belgrade: Institute of Psychology.

Özden, H. Ö. (2002). Beauty Concept İn Pre-Hellenic Greek Philosophy. Journal of AtatÜRk University Teology Faculty, 17, 67-98.

Polat, S., \& Kavak, Z. (2011). Aesthetic Leadership (AL): Development and Implementation of Aesthetic Leadership Scale (ALS) Of The School Directors, Educational Research And Reviews, 6(1), 50-61.

Ruen, K. K. (2010). Teaching Toward Wholeness the Aesthetic in Education. Sarah Lawrence College, 23(2).

Samier, E. A., Bates, R. J., \& Stanley, A. (2006). Aesthetic Dimensions of Educational Administration and Leadership. London: Routledge.

Sauer, E., \& Ropo, A. (2007). Aesthetic Knowledge Production and Consumption. Paper to Be Presented in the Third Organization Studies Summer Workshop. Crete, Greece, 7-9.

Schroeder, J. E., \& Fillis, I. (2010). Aesthetic Leadership, Research Handbook on Political And Civic Leadership. Richard Couto (Ed.). London: Sage.

Smith, R. A. (1996). Leadership as Aesthetic Process. Journal of Aesthetic Education, 30, 39-52. http://dx.doi.org/10.2307/3333179

Taylor, S., \& Hansen, H. (2005). Finding Form: Looking at the Field of Organizational Aesthetics. J. Manage. Stus., 42(6), 1211-1231. http://dx.doi.org/10.1111/j.1467-6486.2005.00539.x

Tebiş, C. (2010). The Relationship of Community-Individual-Art Education. E-Journal of Kent Academy. http://www.kentakademisi.com/toplum-birey-sanat-egitimi-iliskisi/12802/30june 2014 monday, 21:42:26.

Vondey, M. (2010). An Aesthetic of Imagination and Creativity for Leaders. Regent University Press, 1, 1-12.

Vural, G. (1997). Leadership and Nursing. Journal of C.U Nursing High School, 1, 15-22.

Woodwar, J. B., \& Funk, C. (2010). Developing the Artist-Leader. Leadership, 6(3), 295-309. http://dx.doi.org/10.1177/1742715010368768

Zhang, H., Cone, M. H., Everett, A. M., \& Elkin, G. (2011). Aesthetic Leadership in Chinese Business: A Philosophical Perspective. Journal of Business Ethics, 1, 475-491. http://dx.doi.org/10.1007/s10551-011-0734-z

\section{$(\mathrm{Cc}) \mathrm{BY}$}

This work is licensed under a Creative Commons Attribution 3.0 License. 